Article

\title{
From Integration to Solidarity: Insights from Civil Society Organisations in Three European Cities
}

\author{
Viviana d'Auria *, Racha Daher and Katharina Rohde \\ Department of Architecture, KU Leuven, 3001 Leuven, Belgium; E-Mails: viviana.dauria@kuleuven.be (V.d'A.), \\ racha.daher@kuleuven.be (R.D.), katharina.rohde@kuleuven.be (K.R.) \\ * Corresponding author
}

Submitted: 11 July 2018 | Accepted: 24 September 2018 | Published: 20 December 2018

\begin{abstract}
This article sheds light on the lack of cohesion in asylum approaches between EU member states and questions the dominance of the 'integration' paradigm. It argues that civil society organisations (CSOs) have, through solidarity, challenged the bias 'integration' involves and the exclusion it generates. To do this, it examines three case-based practices led by CSOs that operate in three European capital cities-Rome, Brussels and Berlin-and that embrace mobility in the context of front-line, transit and destination countries, respectively. With the 'refugee crisis' of 2015 acting as a threshold moment, the cases navigate a complex web of relationships amidst a fragmented debate about asylum, and varying national and local frameworks in Europe. Through the comparison of cases, the article argues that the political possibilities of such practices and their enduring engagements with the urban, remain limited. However, the shift in discourse from 'stasis' and 'integration' to 'mobility' and 'solidarity' that the three cases embody, represent a critique that fundamentally challenges urban planning and its role for asylum.
\end{abstract}

\section{Keywords}

asylum; civil society organisations; displacement; integration; solidarity

\section{Issue}

This article is part of the issue "European Cities Planning for Asylum", edited by Frank Eckardt (Bauhaus-Universität Weimar, Germany).

(C) 2018 by the authors; licensee Cogitatio (Lisbon, Portugal). This article is licensed under a Creative Commons Attribution 4.0 International License (CC BY).

\section{Introduction}

Although not a new phenomenon, the most recent migratory flows seeking to reach Europe touched a peak in 2015, earning the well-known, but highly controversial term, 'refugee crisis'. That year the EU received 1.3 million asylum applications (Eurostat, 2018), creating a condition of emergency, due to the large number of people arriving at the same time. Arguably the 'refugee crisis' was not one created by incoming asylum seekers per se, but one provoked by the incapacity of the EU to sufficiently cater for such large amounts of displaced people at once (Doomernik \& Glorius, 2016). Thus, the 'refugee crisis' questioned Europe's position vis-à-vis the refuge and hospitality of those displaced by war and other serious disruptions, becoming a threshold moment for Europe's political and social project, as well as a challenge for the entire refugee system (Betts \& Collier, 2017).

With the EU-Turkey agreement, the EU-Libya deal, and the closing of the Balkan route, the number of asylum applications in Europe dropped in the course of 2016 and 2017 (Eurostat, 2018). This number may well diminish in light of the most recent EU summits that have practically "buried the right to asylum in Europe" (Taylor, 2018 , p. 20). Moreover, migration has become increasingly enmeshed with the future of many urban areas in Europe, since cities and metropolitan regions persist as main sites of arrival and passage for displaced people (Eurocities, 2016). They are, by consequence, a crucial concern for urban planning, which here is understood as 
"a broad set of social activities not limited to traditional planning efforts, but rather as purposeful social action to improve the quality of life in localities, cities, regions and nations" (Sanyal, 2005, p. xxi).

These activities engender transformations with spatial and social consequences that manifest themselves in the city, linking urban space and displacement, and further rendering migration and asylum urban phenomena within which local level responses are very much involved. It is because of this reasoning that cities have been set as the stage for the cases that will be discussed in this article, as they spotlight activities related with asylum seekers in the city, in line with Darling's call for "the need to better unpack the urban character of asylum" (Darling, 2017, p. 180). In the three urban areas presented here, as well as in many other cities across Europe, civil society organisations (CSOs) have been mobilising locally, occupying different positions vis-à-vis state-led approaches. Solidarity is at the core of their actions, confirming the importance of revisiting the term in light of diversity, and more specifically, by taking into account how it is practiced in everyday places by people engaging across ethnic and cultural boundaries (Oosterlynck, Loopmans, Schuermans, Vandenabeele, \& Zamni, 2016). These mobilisations therefore, hold potential to engage "the city as a space distinct from, yet conditioned by, state discourses and practices" (Darling, 2013, p. 1786).

By unfolding the stances taken by local practices led by CSOs in the three European capital cities of Rome, Brussels and Berlin, this article sheds light on the lack of a unified approach to asylum embraced by European member states. Before delving into the cases, the article will begin by reviewing integration based on recent literature, as evidence that challenges the problematic embedded within it. It will then attempt to unpack solidarity as it is expressed through civic action, intentionally straying away from forming a definition for it that is simplistic of its complexity. The main aims are to highlight how CSO practices enact solidarity as everyday relations that take place in urban spaces, and to assess the political possibilities of such solidarities for urban planning. In fact, while these initiatives are not linked with main state institutions and NGOs traditionally working on integration, it remains to be seen if new voluntary initiatives born in the aftermath of the 'refugee crisis', such as those examined below, will be bypassed by mainstream integration policies or will be able to radically renew them. Because of the politics of bounding entailed by the 'refugee crisis' (Crawley \& Skleparis, 2017), the authors will rely on the terms, 'asylum seeker' to refer to people in the process of seeking asylum, 'refugee' to indicate those that are status holders, and 'displaced' to describe a broader group of mobile people having experienced flight and trauma.

\section{Apprehending and Questioning Integration}

When it comes to issues related with migration into or around Europe, integration has become a prevalent approach (Favell, 2013). While a decade ago it could still be claimed that it was a key term for the development of policies aiming at refugees and asylum seekers (Ager \& Strang, 2008, 2010), it has since been challenged by many scholars both conceptually and operationally (Bagelman, 2013; Darling, 2017; Favell, 2013; Gryzmala-Kaziowska \& Phillimore, 2017; Squire, 2010). Yet, a lack of shared understanding and no generally accepted definition persist, despite being already pointed out to for several years now (Castles, Korac, Vasta, \& Vertovec, 2002; Robinson, 1998). Its articulation in the last decades as a "long-term two-way process of change" (ECRE, 1999) appears to recognize that mutuality is key toward achieving a welcoming environment. However, research has shown that the dominant interpretation of integration remains an effort to be made mostly by those who have newly arrived, since the notion is embedded in conceptions of the nation-state which are exclusive and culturally bounded (Favell, 2013; Squire, 2010). It is rooted in the assumption that privileges 'established' residents, puts the burden on refugees to integrate, and neglects asylum seekers as those with ephemeral presence. Because of such assumptions, Squire (2010) argues that it is important to shift from the rhetoric of integration to that of solidarity, which removes the expectation of assimilation.

Ager and Strang's work on integration has attempted to reflect on the normative conceptions of integration by outlining a framework in which they develop ten core "integration domains" (Ager \& Strang, 2008, p. 167). Of these areas the most foundational, citizenship and rights, is viewed as requiring utmost articulation by governments intending to develop an effective integration policy (Ager \& Strang, 2008, 2010). Such categorisations reflect the way in which responses to asylum seekers and refugees are approached at the governing level. Integration structures generally begin from a privileged standpoint that reduces and simplifies the complexities of displacement, and accepts the nation-state's framework of categorising people, as worthy of integration by being with status or without. In addition, such approaches to integration are, as Squire has argued, flawed because they "overlook(s) enactments of solidarity in which cultural categories and legal distinctions disappear or are relatively unimportant" (Squire, 2010, p. 292). She has illustrated the need to consider the more recent collective engagements (in the UK) as movements that enact a shift of focus away from integration toward solidarity that is mindful of temporary presence and mobility (Squire, 2010). Comparably, this article presents the three cases as actions that set aside cultural and legal distinctions by practicing solidarity with varying degrees of opposition from local and national policies, thus, occupying distinctive spaces within their respective urban settings.

Integration is also being redefined by the shifting relationship between migration and forms of settlement, a point of particular relevance for urban planning. In the past, patterns of movement consolidated the con- 
cept of migration as leading to permanent resettlement (Penninx, Spencer, \& Van Haer, 2008). By contrast, in the hypermobile globalised world of today migratory practices are more in flux than they were in the past, and by consequence integration "cannot be what it was" (Favell, 2013, p. 54). This is ever more the case in the context of asylum seekers and refugees who have been moving through Europe as a result of the circulatory movement induced by the Dublin Protocol, that instigated situations of being expelled and suspended (Agier, 2016; Nail, 2015). These forms of mobility refute the essence of integration that is tied to permanence and to a conception of "a bounded national society defined by more or less inclusive rules of membership" (Favell, 2013, p. 54). Because of the state of suspension and related debilitating issues that come as a result of not having any status, Bagelman has argued that displaced people often have to succumb to a life of charity and waiting (Bagelman, 2013).

In light of this, the cases presented aim to show how initiatives led by CSOs manifest themselves in three urban areas in Europe and are critical to challenge dominant conceptions of integration through solidarity. In studying their practices, what emerges is that solidarity is a process deeply rooted in human values and camaraderie, especially workable at the local level through the mobilisation of citizen groups and CSOs, notwithstanding the importance of multi-level governance. While scholarly work on higher level frameworks such as Ager and Strang's ten core domains remain important to note interrelations between housing, workplaces, neighbourhoods and public services, solidarity plays a major role as the main ingredient for two of the core domains they define, namely those of social bonding and bridging (Ager \& Strang, 2008).

The three cases that follow, in Rome, Brussels and Berlin, vary in their durational set-ups, from (initial) emergency responses to long-term urban transformations, and face different struggles in regard to local and national support. While both the Baobab Experience in Rome, and the Plateforme Citoyenne de Soutien aux Réfugiés (the Citizens' Platform for the Support of Refugees, which will be referred to as PCSR in this article) in Brussels emerged from immediate action of volunteers during the intensified movements of 2015, the Coop Campus in Berlin is the outcome of a longer term engagement initiated in 2012 through voluntary action. All three cases take a stance in the face of EU frameworks foregrounding 'integration' and specific national interpretations of the term, as we will see in the discussion below.

\section{Insights from CSOs in the Aftermath of the 2015 'Refugee Crisis'}

In the aftermath of the 'refugee crisis' of 2015, conditions have evolved since the first citizen-led mobilisations - many of which have subsequently associated themselves formally into CSOs and NGOs (Bouagga
\& Barré, 2017; Mikaba, 2016). They continue their work today by broadening their efforts to include displaced persons in the context of an increasingly diversified population and pursue awareness-building activities in relation to asylum and its urban implications. In such context, cities and municipalities have capitalised differently on the vibrancy of such mobilisations. Whether this dialogue has occurred or not is a point worth expanding on in relation to urban planning issues. In fact, when the notion of 'urban planning culture' emerged, it supported the debate on whether a particular autonomy and self-governance embedded in a specific locale would resist in the face of escalating encroachment by global forces (Sanyal, 2005). Relatedly, one of the founding fathers of 'radical planning', John Friedmann $(1987,1988)$ argued that civil society would defend what he termed life space in the face of global forces. In his view, such resistance would be legitimised by a different form of planning, aimed ultimately at the empowerment of civil society (Sanyal, 2005). The comparison of the three cases displays, therefore, whether such alternative form of planning is emerging in light of the political possibilities claimed by and provided to the CSOs examined. These possibilities are reflected in the actual physical spaces and places of the cities in question, as will be further described below.

The research presented here is part of an ongoing collaboration between KU Leuven, the University of Sheffield, Politecnico de Milano, Housing Europe, and Architecture without Borders International. In terms of the information and data collection for the cases presented in this article, the three authors typically conducted research on each of the cases in parallel, however their time-frames varied. In the Italian case, semistructured interviews with volunteers and key organisers were conducted, and additional desktop research included access to the CSO's digital archive. In the Brussels case, digital and spatial ethnographic research as well as informal conversations and semi-structured interviews with CSO members took place in the course of 2017. In the German case, contacts with contributors to the project preceded the specific focus of this research. Semistructured interviews with key organisers and urban practitioners were also conducted, and events organised by the CSO in question were attended as moments to pursue conversations informally.

Each of the three cases will be unravelled by focusing on two particular aspects. Firstly, the everyday practices of the CSOs will be discussed in light of particular activities that reflect the dynamic engagements between asylum seekers and refugees and more 'established' residents, and that at the same time contribute to solidarities that cut across such distinctions. Secondly, the transformation of their activities over time will be deconstructed to illustrate how a focus on mobility and solidarity impacts the range and nature of the CSO practices. A comparative reflection on how the urban plays out for each case will follow, together with a discussion on what 
the political possibilities for each CSO are, in the context of a nuanced and complex web of relationships that reflect the planning cultures they are embedded in.

\subsection{The Baobab Experience: Rome, Italy}

In general terms, in spite of its central position along migratory routes to Europe, Italy occupies an ambivalent position, because it is unclear how many of the asylum applicants will actually remain in the country (Scholten et al., 2017). The number of asylum requests reached a peak in 2016, with 130,119 applications, of which 58\% were refused (Ministero dell'Interno, 2018). Yet, dominant narratives persist in presenting Italy as a country primarily of transit, leading to a fragmented asylum policy and a high focus on emergency relief and first reception (Omizzolo, 2016; Protection System for Asylum Seekers and Refugees [SPRAR], 2017), despite the stark rise in applications since 2014. Since 2002, following a first rise in asylum applications in the late 1990s, the idea of "360 degree integration" was endorsed by the establishment of the SPRAR. The intention was to move beyond the distribution of basic services and to provide complementary support in the form of 'integrated reception' undertaken by local institutions on a voluntary basis, with a $20 \%$ co-financing requirement. The SPRAR's prime shortcoming is that it remains inaccessible for the large majority of asylum applicants, since in $2016,77 \%$ of them were still hosted in 'extraordinary' reception centres (Lunaria, 2016).

The city of Rome illustrates how the difficulties of the Italian asylum system play out in its urban arena, where over 100 unused structures are inhabited by displaced persons-estimated to be over 180,000 in the capital (Busby \& Dotto, 2018). Many of them reside in emergency accommodations and thousands live in makeshift squats - approximately 10,000 live in inhumane conditions (Médecins Sans Frontières, 2018). It is in this context that the Baobab Experience was born in 2015, when an emergency situation was created by the simultaneous clearance of informal camps and the suspension of the Schengen agreements (Baobab volunteers, 2016). Baobab emerged out of a self-managed accommodation centre run by migrants that offered approximately 200 beds for overnight stays, as well as informal support of various nature. Its evolution over time is the result of both, specific local policies and fundamental solidarity practices that have engendered dynamic transformation of its undertakings.

Cleared more than 20 times from its various sites of occupation, the Baobab Experience currently takes the form of an informal camp occupying a no-man's land behind the Tiburtina Station in Rome. The area has been renamed Maslax Square after a migrant whose tragic path is considered emblematic of the "dehumanisation of Italy's reception system" (Baobab, n.d.). For the moment, the camp's presence has been enabled by the area's owner, National Railways. Even though Roman authorities remain a potential threat, it has been almost a year since they have performed further clearance actions. In the camp, activities take place with the support of local and international medical and legal associations, as well as the broader network established with human rights activists. By 2018 , more than 70,000 people had passed through the Baobab camp (Baobab, n.d.), received medical care, food, overnight accommodation, and legal assistance, all set up by citizen donations. They were women, men and children aiming to reach other European countries, or asylum seekers in Italy who were exposed to lengthy waiting lists before being able to access support as a result of their undefined statuses.

The centre has been described by its volunteers as a place where "not just migrants have transited, but where an entire humanity has been in transit" (Baobab, n.d.). By this they not only refer to the fact that participating as an 'established' urban resident implies the challenge of decentring one's position when confronted with a wide array of mobile trajectories and migratory projects, but they also underline the variety of categories that have contributed to the running of Baobab's everyday activities (L. Cantisani, personal communication, 19 September 2018). This range includes both very young and very old residents of the nearby neighbourhood, as well as entire families, students, and foreign tourists who decided to spend part of their travels through Italy acting as helpers.

Notwithstanding the fact that local authorities have committed to providing a definitive venue for Baobab, the City of Rome has refused all attempts by the CSO to find a permanent location, even when they included participation in public calls for the regeneration of abandoned industrial buildings and landscapes (A. Costa, personal communication, 6 July 2018). Nonetheless, the centre's precarious occupation in space has not been an obstacle for the provision of support, which extends beyond 'first reception' and is not limited to the, however significant, food provision, emergency shelter, and medical and legal assistance. This care is extended to all those who require it; this may include migrants with acquired refugee status, but who have not been able to access a number of services due to various factors, including discrimination (A. Costa personal communication, 6 July 2018), as well as Italian nationals in precarious conditions (L. Cantisani, personal communication, 19 September 2018). As such, the centre distinguishes itself from mainstream providers who 'deliver' specific forms of assistance only to those 'entitled' by means of particular classifications and categorisations.

Two particular activities are worth exploring in the context of enacting solidarity; both subvert conventional categorisations that result from differential management of migration in Europe. The first activity worth examining is Baobab4Fun. This initiative is a collaborative venture between camp volunteers and hosts, and concerns leisure and cultural activities, ranging from language classes, urban gardening, sports and tailored arts and crafts workshops. More significantly, the group also 
organises guided tours in Rome, including visits to major attractions such as, archaeological sites and museums. While many displaced people are careful about avoiding activities that may draw attention to their identities, the guided tours legitimise their participation through presence and change their relationship to the urban realm, which they experience largely by attempts to remain invisible. Moreover, sightseeing is not organised as an initiative exclusively for the displaced, but rather, as an opportunity for broader participation. What is commonly framed as an activity for mobile elites, such as global tourists, becomes therefore accessible to several participants-including asylum seekers and refugees.

The second area of intervention worth scrutinizing is Baobab4Jobs. This initiative focuses on various forms of support for displaced people to pursue their aspirations of further studies, or the acquisition of skills and training. This is yet another domain of action that illustrates how the Baobab experience is not only a 'first reception' provider, but one that has over time extended and modified its own support to cater to a broader array of activities, given the wide diversity of participants present in the camp. Again, no distinctions are made: "while some hosts stay in the camp for three days, some stay for six months or more while waiting for their documents. So that this time is used productively, everyone will have the opportunity to attend practical training courses" (Baobab, n.d.). Starting September 2018, based on the idea of one of the camp's hosts, further training will be brought to the camp's space itself, under the rubric of "Baobab unique experience on skill acquisition" (Baobab, n.d.). The initiative is not only significant because it is initiated by a 'receiver' rather than a 'provider' of aid, but also because it multiplies and diversifies the range of activities the camp holds within its physical and social environment. On the one hand the camp confirms its rootedness in the self-initiatives of migrants, and on the other, it strives to reduce the state of exception that camps generally embody by becoming increasingly varied, both in program and social composition.

\subsection{The Plateforme Citoyenne de Soutien aux Réfugiés: Brussels, Belgium}

Institutional structures in Belgium operate at three levels: federal, regional, and communal. While asylum and migration are a federal responsibility, policing, public order, and social policies overlap in responsibility between the federal, the regional and the communal; urban planning is a responsibility shared by the region and the communes. In Brussels this framework leads to significant overlap: the city has 19 communes, each with its own mayor and administration; they all further fall into a regionalized administration, the Brussels-Capital-Region. Because of this complex and nuanced institutional structure, overlaps exist in the governance levels, creating opportunistic gaps that open up the possibility for negotiation by the group in question, as will be elaborated.
In 2015, the state received a relatively large number of asylum applications when confronted with its population size (Scholten et al., 2017, p. 12). That year, Brussels saw the emergence of a spontaneous refugee camp in Maximilien Park (which lies in proximity to the immigration office), as a result of the long waiting times it took asylum seekers from Syria to file their applications. Under the leadership of far-right Secretary of State for Asylum and Migration, Theo Francken, official response had deliberately expressed hostility to those displaced (Cendrowicz \& Paterson, 2015). In the absence of timely institutional action, non-profit organisations, citizen groups, and individual volunteers mobilised to offer humanitarian service, supporting the installation of the camp and giving rise to the PCSR. The camp has been studied as a contested site for citizenship (Depraetere \& Oosterlynck, 2017) and as an expression of the political activism of humanitarian workers (Lafaut \& Coene, 2018); this includes partial insight into the work of PCSR. Its members are heterogeneous and consist of political activists of anti-austerity movements, action committees of undocumented migrants, students, and volunteers (Lafaut \& Coene, 2018). PCSR is the CSO that will be examined in the context of the Belgian capital city and its recent entanglements with migration.

The evolution of PCSR's mobilisation over time can be examined in relation to the changing demographic of displaced people in Maximilien Park, following the clearance of the Calais 'jungle' in October 2016. These demographic changes form the basis, in this section, for discussing how solidarity and mobility have evolved in PCSR's activity and the implications for its action in the urban realm. PCSR began as an immediate response to the 2015 'crisis', in an attempt to put pressure on the Federal Government to take action under the state's obligation to the 1951 Refugee Protocol (Marques dos Santos, 2018). An evolution in its activity would allow it to negotiate a deal with the City of Brussels to dismantle the camp in exchange for the temporary rights-of-usage of a vacant factory; this evolution is characterized by the moment when PCSR members collectively decide to offer asylum seekers sleeping space in their homes to display solidarity with them (Cendrowicz \& Paterson, 2015). This solidarity has not only persisted but has also grown in light of a change in the profile of asylum seekers, who are no longer the "good refugees" of Syrian origin (Lafaut \& Coene, 2018, p. 9), but the less welcome sub-Saharan African men and women frequently denigrated under the appellation, 'transit migrants'. For reasons again connected to terminology (Düvell, 2010) the term 'displaced' people will be preferred instead.

For many of those displaced currently in Maximilien Park, disappointment in European hospitality has led them to consider the UK as a last resort to seek asylum (Pellecchia \& Godderis, 2018). In the meantime, they experience a state of suspension, since they have not filed for asylum in Belgium nor yet reached the UK, their applications in other EU member states may have been re- 
jected, or they have been fingerprinted upon entry into Europe but have moved on from their first country of arrival. Since this change in the demographic of those displaced seeking refuge in Maximilien Park, PCSR has expressed "solidarity with all migrants" (PCSR, 2017). This slogan reflects the platform's evolution from a citizenled mobilisation generated by public sympathy for Syrian refugees, to a broader movement that critically engages with issues of asylum in Europe.

According to its website, PCSR stands in opposition to the hostile environment in Belgium and in support of "migrants" (2017); they do not distinguish between less or more privileged mobile people, their mobility statuses, or their categorisations. The platform aims "to be a place where people can meet...nurture ideas and initiatives that promote solidarity between citizens and migrants...[where they] will engage in awareness-raising activities and mobilize people around migration issues" (PCSR, 2017). The website also stresses that Europe needs migrants, but never once uses the term 'integration', and rather focuses on the term 'solidarity'. According to one of their key members, "hosting" and "including" are key terms for the platform, as opposed to "integrating", especially under current conditions of secondary movement within Europe (Marques dos Santos, 2018). PCSR's action reverses the bias embedded in 'integration'-that those who are new are expected to integrate-and focuses its attention to the host society's role in promoting a culture of hospitality, feeding what Darling (2013) has examined under the notion of "moral urbanism".

PCSR self-organises mainly via Facebook, through a closed online group with over 42,000 participants (Hébergement Plateforme Citoyenne, 2015) and more than 15 area-based local groups. Members volunteer sleeping space in their private homes all over the country, acting as hosts to those in need for as many nights desired. This process goes beyond the provision of bedspace; it is one in which cultural exchanges take place and misconceptions about one another are broken. In analysing their action, four primary acts of solidarity are enacted: offering asylum seekers a place to sleep during the night, offering them a ride to and from the park, donating supplies, and sharing live warnings of police presence in the district. Secondary activities include organising gatherings of protest, such as rallies that defend a cause, or of community events such as meals and parties. Tertiary activities include posting interesting articles, political updates that are relevant to migration, as well as spreading information to raise awareness and provide mutual advice among hosting members.

While PCSR communicates and organises online, it uses the city for its operation. Since Maximilien Park has acted as a place of arrival, hosting asylum seekers and offering its infrastructure for their use, it has also been activated as PCSR's main meeting point for the dispatch of daily action. Moreover, due to the multi-layered governance structure outlined above, PCSR has found gaps that have allowed them to negotiate the opening of humanitarian and reception centres that mark its presence physically and spatially. One of such instances is the recent establishment of 900 square meters of space for centralising medical, legal, social, and other services offered by several local and international CSOs (Marques dos Santos, 2018). This space has been secured in none other than the North Station-the busiest multimodal station in the country, and an international bus stop for low-cost pan-European lines. While the humanitarian nature of the hub makes it less easy to disengage from discourses that view those displaced as victims, the online stories of PCSR members hosting asylum seekers in their private homes testify to exchanges that refute the distinct roles of 'recipients' and 'providers' of aid. Neologisms such as "vnous" (combining 'us' and 'them') and "amigrant" (merging 'friend' and 'migrant') developed in the course of exchanges between volunteers and those displaced are a telling indication in this regard (Daher, 2018).

Furthermore, PCSR also successfully negotiated to temporarily occupy a vacant office building to act as a nightly reception centre, La Porte d'Ulysses (Marques dos Santos, 2018). This centre is one out of multiple urban spaces the PCSR operates in: it acts at the unit scales of the individual hosts' homes and participates in the running of two humanitarian hubs as well as several support centres. Building on Darling's call to reflect on the city's engagement with forced migration (Darling, 2017), this shows how acts of solidarity have a direct urban planning implication that is tied to the city, not only in its representations, but also in its physicality. PCSR's activities further reflect the solidarity of collective citizen action that Squire (2010) writes about, enabling it to move between spatial and legal scales, making use of interstitial spaces both in the city and between governance levels.

\subsection{Coop Campus: Berlin, Germany}

Germany has been the largest receiver of refugees in Europe during the 'crisis' of 2015 (Romei, EhrenbergShannon, Maier-Borst, \& Chazan, 2017). It appears to be a desired destination because it is associated with a prosperous economy, liberal asylum laws, and strong diaspora networks (Trines, 2017). The registration and administration of asylum seekers for the whole country is steered by its main institution, the Federal Ministry for Migration and Refugees (BAMF), while the implementation of actual 'integration' happens at the local level. States and municipalities are responsible for distribution, education, housing, and the provision of material supplies for asylum seekers and refugees, and correspondingly, follow very different approaches. In Berlin these numbers were reflected in the influx of 72,000 displaced persons in 2015 and 2016 (The Senate of Berlin, 2018). The number of arrivals challenged the state apparatus, causing the federal administration to collapse-a situation that triggered a quickly growing number of volun- 
teer networks to setup alternative support systems. In July 2016, the Senate of Berlin developed a Masterplan of Integration and Security, with the important characteristic of being applicable only to status holders (The Senate of Berlin, 2016). This highlights what Squire has exposed as the disqualification of asylum seekers as "subjects of integration and cohesion" (Squire, 2010, p. 291) due to their undecided or ambivalent status.

The Gärtnerei-later expanded to become the Coop Campus-is one example that deliberately targets primarily, but not exclusively, the participation of nonstatus holders to the city's social, cultural, and economic life. One of the project's goals is to avoid that displaced persons stay in limbo, and to employ collaborative activities to halt the endless cycle of waiting that most are subject to (Schlesische 27, 2017). It is an experimental garden and nursery located in the Western Jerusalem cemetery that borders the Tempelhofer Airfield in Berlin-Neukölln, comprising an area of 3000 square meters. It is owned by the Protestant association Berlin-Stadtmitte (EvFBS), which is in the process of reclassifying the cemetery into building land. The team of the Schlesische 27, an International youth and cultural centre located in Berlin-Kreuzberg, and Raumlaborberlin, the auto-depicted "commons of spatial practice" (C. Mayer, personal communication, 2 July 2018) are the initiators of the Gärtnerei/Coop Campus. The EvFBS supports the initiative by allowing the free use of the cemetery ground. However, the current cooperation agreement is temporary, and has already been renewed a few times; its further renewal remains uncertain.

The Gärtnerei/Coop Campus initiative emerged out of earlier engagements of the Schlesische 27 acting in solidarity with asylum seekers and refugees. The team had already participated in the refugee-led Oranienplatz occupation by the Lampedusa in Berlin group, that evolved out of a 2012 march, in which around 70 displaced persons predominantly from West Africa, as well as 100 supporters, protested against the inhumane conditions in the country. The gradual occupation of the square turned into a tent village where approximately 100 refugees lived, until they were evicted in 2014 (Rohde, 2016). The Refugee Company for Crafts and Design and the related Cucula project were born out of a direct engagement by the Schlesische 27 with the occupation (Cucula, n.d.). Other projects followed suit with the predominant goal of supporting asylum seekers and refugees to work rather than to wait.

The Coop Campus project is considered a phase in a gradual transformative process of city-making (C. Mayer, personal communication, 2 July 2018). It began in 2015 as a nursery aiming to tackle, through gardening, the question of how to enable the coexistence of diverse groups after the significant amount of those displaced had arrived in Berlin (Schlesische 27, 2017). It was set up in mutual effort between the project's initiators, asylum seekers and refugees, and neighbours. This collective engagement was a way to establish and upkeep a sense of mutual ownership over the project. The nursery emerged as a first intervention, followed by the restoration of an existing stonemason's house, and the installation of a greenhouse to become a multi-functional, experimental garden. To create opportunities for enabling active participation is, as already mentioned, the prime aim of the Coop Campus, underlined by its approach to empower people through the exchange of skills and knowledge. The woodworking workshop in the stonemason house for instance, provides the possibility for participants to work independently of legal status. A kiosk was further constructed for the exchange of products and donations that activate displaced people's skills rather than fostering the passive reception of state support.

The site's incremental transformation emphasizes the conception of urban inclusion as promoted by the Schlesische 27 and its partners. Coop Campus is described as providing a ground for mutual learning amongst a heterogeneous group of participants, while offering to be the learning ground itself (Schlesische 27, 2017). It, therefore, emphasizes a collective approach to articulate the coexistence between 'established' residents and those displaced. Solidarity is expressed by embracing participation through presence, rather than through membership based on legal or cultural characteristics. Learning is a multi-directional process that is grounded in the transformation of an urban interstice; gardening, building, and a plethora of other activities are shaped through collective engagement and are thus, constituted in spaces where various legal statuses, socioeconomic profiles, and cultural and ethnic backgrounds have the opportunity to engage with one another. Distinctions are blurred by the fact that all participants are learners and have some form of knowledge to share with the others present. Interested participants have the possibility to learn German in a school in the garden, set up in a stonemason house that also hosts a monthly adult education activity known as Café Nana. Here too, boundaries are blurred and categories subverted: asylum seekers and refugees provide different language classes to Berliners and share insights into customs, ceremonies or agricultural practices in their home countries.

The gradual changes made to an urban area serve as the canvas for a co-creative process that not only enacts solidarity, but also transforms the urban fabric physically. From a gardening nursery, the Coop Campus has evolved into a collective process that includes the contribution of a wide array of participants on site. The project is indeed meant to function as a testing ground where ideas for a broader urban situation are tried out and could stimulate further collective developments (C. Mayer, personal communication, 2 July 2018). However, the hurdles that the project faces today are indicative of the clear limitations when it comes to the potential endurance and wider impact of collective engagements rooted in solidarity. Indeed, while social hierarchies and distinctions may be momentarily disrupted, the long-term vision for social and physical change has stalled, despite an urban 
planning framework by Raumlaborberlin for the gradual development of the area as a cooperative neighbourhood beyond the cemetery's perimeters. Even though the project illustrates how socio-cultural spaces are appreciated, as does the approach towards collective urban development (C. Mayer, personal communication, 2 July 2018), neither the EvFBS nor the responsible planning authorities are open to this vision. Another related fact is the abandonment of the initial idea to develop housing for both refugees and non-refugees in the nearby communal living complex by EvFBS. Because of the difference in housing standards for refugees and conventional social housing, these intentions could not be pursued.

\section{Embracing Mobility to Shift from Integration to Solidarity}

The three cases presented above provide evidence, from practice, of the shifting discourse at the local level from integration to solidarity, through the perspective of mobility. By mobilising citizens under a shared value system that does not distinguish between the status of people as a precondition to access the city, they display solidarity as a process that foregrounds participation through presence, rather than exclusive membership rules rooted in legal and cultural statuses. They either deliberately shun the framework of 'integration', as does PCSR in Brussels, or, as in the case of Baobab in Rome, they emphasize that neither temporal nor legal boundaries should be an obstacle to welcoming the displaced-even if the term can still occasionally be found in their digital and printed publications. Comparably, the Coop Campus team has involved non-status holders, without making them an exclusive target of support, to promote the stimulation of an urban environment where intensified movements and diversities can generate a multitude of collective engagements. Further research may wish to explore the important entanglements that such practices based on solidarity may have with representations of the "good" and "hospitable" city called for by Derrida (2001) and observed by Amin (2006) and Darling (2013); this, however, is not the prime focus of this contribution.

Rather, through the comparative analysis of three cases, this contribution displays the tangible consequences of EU migration policies and their national interpretations on urban space, and how the circulatory and secondary movements, the multiplication of borderlands, and the diversification of migratory projects, have impacted a number of European cities (for a list of cities dealing with a "fluid situation, often in the absence of support, or even in the face of hostility from the national level", see Eurocities, 2016, p. 7). This impact is multi-faceted but is here discussed in light of, firstly, the political possibilities of CSO-driven solidarity in feeding what has been termed, "life space" (Friedmann, 1988; Friedmann \& Huxley, 1985), and secondly, the intersection between such mobilisations and the actual urban spaces that enable the enactment of solidarities, as a means to reflect on how the urban plays out in the context of asylum.

For the first point, as mentioned in the introduction, Friedmann advanced the idea that a renewed form of planning would be capable of legitimising planning processes that would ultimately empower civil society (Friedmann, 1988). The latter was viewed as the principal driver of resistance against homogenising forces, mostly understood as economic, albeit extended here to include cultural and social dimensions. However, the political possibilities of the CSO cases examined in the cities of Rome, Brussels, and Berlin display an extreme precariousness; in the best case scenario, they are tolerated and mildly supported by local authorities, as the Coop Campus case shows, but both the Baobab volunteers and PCSR are rather placed in a position of instability. National integration frameworks or local integration plans, as epitomised by the Masterplan on Integration and Security released by the Senate of Berlin, continue to target status holders and exclude many other displaced people without status. While the blurring of such distinctions is at the core of the solidarities enacted by the three CSOs examined, the disruption and unsettlement of social roles and hierarchies (e.g., learners/educators; providers/recipients) remains specific to the activities and initiatives led by the CSOs in question. They find little to no resonance with the way in which various governance levels continue to conceive of permanent settlement, in terms of legal membership and cultural boundedness as the main paradigms to work with displaced people. The key posture remains that of departing from stasis rather than from mobility, thus, dismissing the force of migrant agency (Nail, 2015).

Movement, moreover, as has been illustrated, has informed the ways in which the CSOs have had to operate in their attempt to find space for action in the urban fabric. This brings us to the second point of attention: all three cases suffer from their interstitial presence in the urban realm, characterised by short-term rental agreements for the occupation of underused buildings or residual spaces in their respective cities of operation. The idea of urban change rooted in solidarity, and for which mobility is a given, is in contrast with the possibility of acting out in the city from a less precarious position: Baobab, PCSR and Coop Campus are now forced into interstices such as station backsides, underused buildings and open spaces with quickly changing ownerships, ultimately compromising longevity and the effectiveness of their solidarities.

The mobility that frames their actions is one to which they are also subject, though this occurs with variations across the three cities. In Rome, Baobab's space of intervention remains a camp under threat of eviction by local authorities in a relatively peripheral location, whereas in Brussels, PCSR operates in public domains such as parks and stations, located in close proximity to an important administrative border represented by the Immigration Office. While the most successful in securing an urban 
space into which physical transformations can be designed as a way to generate a co-productive city-making process, Coop Campus too suffers from temporal lease arrangements, and the recent sale of part of the land has endangered the continuity of key activities, such as Café Nana. Through both the Rome and Berlin cases, we see that when longer-term engagements with the city are searched for, obstacles arise. As soon as mobility becomes a vision for city-making for example, the consequences of differential logics arise, as illustrated by the different housing norms in Berlin. Even though the practices endorsing mobility have 'moved' themselves by expanding their focus, broadening their audiences, and expressing solidarity with a growing number of vulnerable people (including 'established' residents facing hardship), clear limitations remain in terms of their wider effects - in spite of the increasing importance of multiple minor acts, based on participation through presence, that disrupt established 'integration' narratives.

\section{Conclusion}

This article has examined three CSO practices that emerged out of the post-'crisis' movements which led private citizens and voluntary associations across Europe to welcome asylum seekers and refugees coming mostly, but not only, from war-torn Syria. This mobilisation shifted from a voluntary instance to organised associational work, that expanded its action over time to include a number of other displaced people for whom 'integration' and its biases are not relevant. To build on such an assumption, the article delves into the recent literature on the term, exposing its discursive and conceptual shortcomings. It then proceeds to critically understand and compare the collective engagements of three CSOs operating in front-line, transit and destination EU countries. The cities of Rome, Brussels and Berlin are the urban realms in which these practices, rooted in solidarity, operate. The cases are unravelled based on two main aspects related to mobility. Firstly, the disruption, suspension and subversion, however temporal, of social, cultural and economic distinctions is discussed in light of the CSOs' engagements. Secondly, the expansion and transformation of their activities is taken as a point of attention to illustrate how, by embracing mobility, the range and scope of CSO engagement can only increase and be enriched.

Taken together, the cases display a shift from the bias of 'stasis' embedded in 'integration', to that of 'mobility' and 'solidarity'. This unfolds through the acceptance of the fleeting presence of not just mobile elites, but also, of other people 'on the move'; it is most significantly expressed in the shared narrative to "break with the established 'script' of the passive and grateful refugee and to undermine fixed classifications of citizens and noncitizens" (Darling, 2017, p. 189). The cases are then discussed comparatively in light of two aspects: first, their opportunity to defend "life space" (Friedmann, 1988) against the disruption of global forces, extended here to include the externalisation of EU migration and asylum policy; and second, the way in which the urban is mobilised, not in terms of representations and imaginaries, but as a physical construct within which to operate, and that can be transformed in alignment with the perspective of mobility. The analysis concludes by highlighting how the endurance of such engagement with the city remains limited, notwithstanding the significant collective engagements grounded in solidarity that confirm the pitfalls of the 'integration' paradigm, and that would require a more 'radical planning' in John Friedmann's terms.

\section{Acknowledgments}

The authors are grateful for the support granted by the KU Leuven Fund for Fair Open Access. They likewise would like to thank the Erasmus + Strategic Partnership, Designing Inclusion, for granting the resources that made this research possible, and the project partners for their insights in the preparatory stages of this investigation. They would also like to thank Ludovico Cantisani, Andrea Costa, Stéphanie Marques dos Santos, Christof Mayer, Barbara Meyer, Maria Michela Mirabelli, Raumlaborberlin and Schlesische 27.

\section{Conflict of Interests}

The authors declare no conflict of interests.

\section{References}

Ager, A., \& Strang, A. (2008). Understanding integration: A conceptual framework. Journal of Refugee Studies, 21(2), 166-191.

Ager, A., \& Strang, A. (2010). Refugee integration: Emerging trends and remaining agendas. Journal of Refugee Studies, 23(4), 589-607.

Agier, M. (2016). Borderlands: Towards an anthropology of the cosmopolitan condition. Cambridge: Polity Press.

Amin, A. (2006). The good city. Urban Studies, 43(5/6), 1009-1023.

Bagelman, J. (2013). A politics of ease. In Sanctuary city: A suspended state (pp. 29-44). Basingstoke: Palgrave Macmillan.

Baobab. (n.d.). The Baobab experience. Baobab Experience. Retrieved from baobabexperience.org

Baobab volunteers. (2016). Baobab experience. In S. Catone (Ed.), Nessun Paese é un'Isola [No country is an island]. Reggio Emilia (pp. 175-182). Reggio Emilia: Imprimatur.

Betts, A., \& Collier, P. (2017). Refuge: Transforming a broken refugee system (1st ed.). London: Allen LanePenguin Random House.

Bouagga, Y., \& Barré, C. (2017). De Lesbos à Calais: Comment l'Europe fabrique des camps [From Lesbos to Calais: How Europe constructs camps]. Neuvy-en- 
Champagne: Le Passager Clandestin.

Busby, M., \& Dotto, C. (2018, February 19). I love Rome, but Rome doesn't love us: The city's new migrant crisis. The Guardian. Retrieved from www.theguardian. com/cities/2018/feb/19/rome-italy-migrant-crisissquatting-emergency-shelters-asylum-seekers

Castles, S., Korac, M., Vasta, E., \& Vertovec, S. (2002). Integration: Mapping the field (Project Report). Oxford: University of Oxford Centre for Migration and Policy Research and Refugee Studies Centre.

Cendrowicz, L., \& Paterson, T. (2015, October 1). Refugee crisis: Belgium dismantles camp as citizens agree to give homes to refugees - but riots continue in Germany. Independent. Retrieved from www. independent.co.uk/news/world/europe/refugee-crisis -belgium-dismantles-camp-as-citizens-agree-to-givehomes-to-refugees-but-riots-a6675881.html

Crawley, H., \& Skleparis, D. (2017). Refugees, migrants, neither, both: Categorical fetishism and the politics of bounding in Europe's 'migration crisis'. Journal of Ethnic and Migration Studies, 44(1), 48-64.

Cucula. (n.d.). Refugees company for crafts and design. Cucula. Retrieved from www.cucula.org/en

Daher, R. (2018, September 8). Borderlands in the transit spaces of Brussels: Solidarity in a hostile environment. Paper presented at the 2018 Annual Conference of the Design History Society Design \& Displacement, New York City.

Darling, J. (2013). Moral urbanism, asylum, and the politics of critique. Environment and Planning A, 45(8), 1785-1801.

Darling, J. (2017). Forced migration and the city. Progress in Human Geography, 41(2), 178-198.

Depraetere, A., \& Oosterlynck, S. (2017). 'I finally found my place': A political ethnography of the Maximiliaan refugee camp in Brussels. Citizenship Studies, 21(6), 693-709.

Derrida, J. (2001). On cosmopolitanism and forgiveness. London: Routledge.

Doomernik, J., \& Glorius, B. (2016). Refugee migration and local demarcations: New insight into European localities. Journal of Refugee Studies, 29(4), 429-439.

Düvell, F. (2010). Transit migration: A blurred and politicised concept. Population, Space and Place, 18(4), 415-427.

ECRE. (1999). Position on the integration of refugees and exiles. Brussels: European Council on Refugees and Exiles. Retrieved from www.refworld.org/docid/ 3df4d3874.html

Eurocities. (2016). Refugee reception and integration in cities. Brussels: Eurocities. Retrieved from solidarity cities.eu/images/RefugeeReport_final.pdf

Eurostat. (2018). Asylum statistics: Statistics explained. EC Europa. Retrieved from ec.europa.eu/ eurostat/statistics-explained/index.php/Asylum_stat istics\#Number_of_asylum_applicants:_drop_in_2017

Hébergement Plateforme Citoyenne. (2015). In Facebook [Group page]. Retrieved October 1, 2018, from www.facebook.com/groups/hebergementplateforme citoyenne

Favell, A. (2013). The changing face of 'integration' in a mobile Europe. Perspectives on Europe, 43(1), 53-58.

Friedmann, J. (1987). Planning in the public domain: From knowledge to action. Princeton, NJ: Princeton University Press.

Friedmann, J. (1988). Life space and economic space: Essays in third world planning. New Brunswick, NJ: Transaction Books.

Friedmann, J., \& Huxley, M. (1985). Transactive planning and life space. Urban Policy and Research, 3(3), 37-40.

Gryzmala-Kaziowska, A., \& Phillimore, J. (2017). Introduction: Rethinking integration. New perspectives on adaptation and resettlement in the era of superdiversity. Journal of Ethnic \& Migration Studies, 44(2), 179-196.

Lafaut, D., \& Coene, G. (2018). "Let them in!" Humanitarian work as political activism? The case of the Maximiliaan refugee camp in Brussels. Journal of Immigrant \& Refugee Studies. Advanced online publication. https://doi.org/10.1080/15562948.2018.1430283

Lunaria. (2016). II mondo di dentro. II sistema di accoglienza per richiedenti asilo e rifugiati a Roma [The world inside. The reception system for asylum seekers and refugees in Rome]. Lunaria. Retrieved from www.lunaria.org/wp-content/uploads/2016/10/II_ mondo_di_dentro.pdf

Marques dos Santos, S. (2018). Parc Maximilien: Repression vs. inclusion. Lecture presented at the DESINC IPHEL 2 Workshop, Brussels.

Médecins Sans Frontières. (2018). Fuori campo. Insediamenti informali: Marginalità sociale, ostacoli all'accesso alle cure e ai beni essenziali per migranti e rifugiati (Secondo Rapporto) [Out of range. Informal settlements: Social marginality, obstacles to access to care and to essential needs for migrants and refugees (Second Report)]. Geneva: Médecins Sans Frontiéres. Retrieved from fuoricampo.medici senzafrontiere.it/Fuoricampo2018.pdf

Mikaba, P. (2016, November 2). Comparative analysis: Voluntary and citizens' initiatives before and after 2015. EC Europa. Retrieved from ec.europa.eu/ migrant-integration/intdossier/comparative-analysis -voluntary-and-citizens-initiatives-before-and-after2015

Ministero dell'Interno. (2018, August 14). I numeri dell'asilo [The numbers of asylum]. Ministero dell'Interno. Retrieved from www.libertaciviliimmi grazione.dlci.interno.gov.it/it/documentazione/stati stica/i-numeri-dellasilo

Nail, T. (2015). The figure of the migrant. Redwood City: Stanford University Press.

Omizzolo, M. (2016). L'accoglienza in Italia: Dall'emergenza strutturale agli Sprar. La buona pratica del Centro Casa Benvenuto a Roma [Reception in Italy: From structural emergency to the Sprar. 
The good practice of the Casa Benvenuto Centre in Rome]. In S. Catone (Ed.), Nessun Paese é un'Isola (pp. 33-64). Reggio Emilia: Imprimatur.

Oosterlynck, S., Loopmans, M., Schuermans, N., Vandenabeele, J., \& Zamni, S. (2016). Putting flesh to the bone: Looking for solidarity in diversity, here and now. Ethnic and Racial Studies, 39(5), 764-782.

Pellecchia, U., \& Godderis, C. (2018). Migrants in Belgium and humanitarian engagement: Stories from the humanitarian HUB, Gare du Nord, Brussels. Paper presented at the 1st Annual CESSMIR Conference 2018, Needs and Care Practices for Refugees and Migrants, Ghent, Belgium.

Penninx, R., Spencer, D., \& Van Haer, N. (2008). Migration and integration in Europe: The state of research. Oxford: University of Oxford ESRC Centre on Migration, Policy and Society. Retrieved from norface.org/wp-content/uploads/2016/07/migration -COMPAS-report.pdf

Plateforme Citoyenne de Soutien aux Réfugiés. (2017, October 12). About us. BxIrefugees. Retrieved from www.bxlrefugees.be/en/qui-sommes-nous

Protection System for Asylum Seekers and Refugees. (2017). Rapporto sulla protezione internazionale in Italia 2017 [Report on international protection in Italy 2017]. Roma: Anci, Caritas Italiana, Cittalia, Fondazione Migrantes, Servizio Centrale Dello Sprar and Unhcr. Retrieved from www.sprar.it/ wpcontent/uploads/2017/11/Rapporto_protezione_ internazionale_2017_extralight.pdf

Robinson, V. (1998). Defining and measuring successful refugee integration. In Proceedings of ECRE International Conference on Integration of Refugees in Europe. Brussels: ECRE.

Rohde, K. (2016, November 24). Re-imagining spaces and cultures in times of crisis. Paper presented at 3rd International Conference on Cultural Relations in Europe and the Mediterranean, Cities as Community Spaces, Valletta.

Romei, V., Ehrenberg-Shannon, B., Maier-Borst, H., \& Chazan, G. (2017). How well have Germany's refugees integrated? The Financial Times. Retrieved from www.ft.com/content/e1c069e0-872f-11e7-bf 50-e1c239b45787

Sanyal, B. (Ed.). (2005). Comparative planning cultures. New York, NY: Routledge.

Schlesische 27. (2017). Die Gärtnerei: An experimental nursery as model for integration and neighborhood. Retrieved from http://www.schlesische27.de/ s27/wpcontent/uploads/2018/01/Dokumentation_ Gaertnerei_web.pdf

Scholten, P., Baggerman, F., Dellouche, L., Kampen, V., Wolf, J., \& Ypma, R. (2017). Policy innovation in refugee integration? A comparative analysis of innovative policy strategies toward refugee integration in Europe. Rotterdam: Erasmus University Institute. Retrieved from www.rijksoverheid.nl/ministeries/ ministerie-van-sociale-zaken-en-werkgelegenheid/ documenten/rapporten/2017/11/03/innovatievebeleidspraktijken-integratiebeleid

Squire, V. (2010). From community cohesion to mobile solidarities: The City of Sanctuary Network and the Strangers into Citizens Campaign. Political Studies, 59(2), 290-307.

Taylor, P. (2018, July 5). EU to migrants: Go home and stay home. Politico. Retrieved from www. politico.eu/ article/europe-migration-refugees-drop-dead-angela -merkel-matteo-salvini-libya-italy-germany-refugees

The Senate of Berlin. (2016). Masterplan of integration and security. The Senate of Berlin. Retrieved from www.berlin.de/rbmskzl/aktuelles/politik-aktuell/2016 /meldung.458963.php

The Senate of Berlin. (2018). Zahlen und Fakten: Zugangslage Flüchtline [Numbers and facts: Arrival statistics refugees]. The Senate of Berlin. Retrieved from www.berlin.de/laf/ankommen/aktuelle-an kunftszahlen/artikel.625503.php

Trines, S. (2017). Lessons from Germany's refugee crisis: Integration, costs, and benefits. World Education News + Reviews. Retrieved from wenr.wes.org/2017/ 05/lessons-germanys-refugee-crisis-integration-costs -benefits

\section{About the Authors}

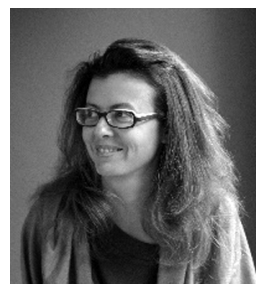

Viviana d'Auria trained as an architect and urbanist at Roma Tre University and pursued studies in Human Settlements at the KU Leuven where she also completed her PhD. She has been Rubicon fellow at the Department of Geography, Planning and International Development Studies, University of Amsterdam, and is currently Assistant Professor at the Department of Architecture, KU Leuven. Exploring 'practiced' architecture is an integral part of her research within a more general interest in the trans-cultural construction of cities and their contested spaces.

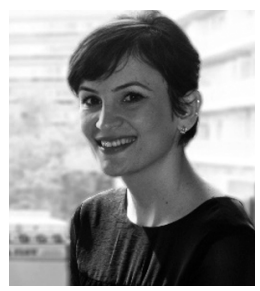

Racha Daher is trained as an Architect And Urban Designer. She currently teaches Urban Design Studio at KU Leuven, and is co-founder of Hive Public Space, an urban design practice that focuses on urban transformation through public space (re)development. She is currently undergoing a PhD on designing for inclusion in an age of movement and migration, exploring mobile social ecologies and their spatial manifestations. 


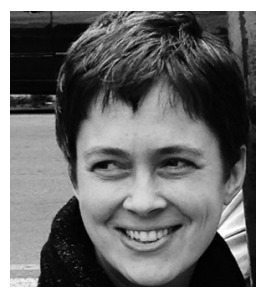

Katharina Rohde is an Urban Practitioner and a PhD candidate at KU Leuven. Her work explores spatial, social and economic inequalities and visualizes inherent strategies of mobile urban actors in the production of space. In reflecting upon her practice, Katharina is currently investigating the agency of migrants in city-making as part of her doctoral exploration within the 'Urbanisms of Pluralism' track. Since 2005 she has been involved in teaching at various universities around the world. 